\title{
Estimation of L-threonine requirements for Longyan laying ducks
}

\author{
A. M. Fouad ${ }^{1,2}$, H. X. Zhang ${ }^{1}$, W. Chen', W. G. Xia', D. Ruan ${ }^{1}$, S. Wang', and C. T. Zheng ${ }^{1}$ **
}

\section{* Corresponding Author: C. T. Zheng \\ Tel: +86-13501532262, Fax: +86-020-61368880 \\ E-mail: zhengcht@163.com}

'Institute of Animal Science, Guangdong Academy of Agricultural Science, Key Laboratory of Animal Nutrition and Feed Science (South China) of Ministry of Agriculture, State Key Laboratory of Livestock and Poultry Breeding, Guangdong Public Laboratory of Animal Breeding and Nutrition, Guangdong Key Laboratory of Animal Breeding and Nutrition, Guangzhou 510640, China

2 Department of Animal Production, Faculty of Agriculture, Cairo University, Giza 12613, Egypt

Submitted Mar 22, 2016; Revised May 16, 2016; Accepted Jun 1, 2016
Objective: A study was conducted to test six threonine (Thr) levels $(0.39 \%, 0.44 \%, 0.49 \%$, $0.54 \%, 0.59 \%$, and $0.64 \%$ ) to estimate the optimal dietary Thr requirements for Longyan laying ducks from 17 to $45 \mathrm{wk}$ of age.

Methods: Nine hundred Longyan ducks aged $17 \mathrm{wk}$ were assigned randomly to the six dietary treatments, where each treatment comprised six replicate pens with 25 ducks per pen.

Results: Increasing the Thr level enhanced egg production, egg weight, egg mass, and the feed conversion ratio (FCR) (linearly or quadratically; $\mathrm{p}<0.05$ ). The Haugh unit score, yolk color, albumen height, and the weight, percentage, thickness, and breaking strength of the eggshell did not response to increases in the Thr levels, but the albumen weight and its proportion increased significantly $(\mathrm{p}<0.05)$, whereas the yolk weight and its proportion decreased significantly as the Thr levels increased.

Conclusion: According to a regression model, the optimal Thr requirement for egg production, egg mass, and FCR in Longyan ducks is $0.57 \%$, while $0.58 \%$ is the optimal level for egg weight from 17 to 45 wk of age.

Keywords: Laying Duck, Requirement, Threonine

\section{INTRODUCTION}

Threonine (Thr) is a crucial amino acid for poultry nutrition because it is the third most limiting amino acid and its metabolites are required for normal metabolism [1]. Thr is essential for mucin production, which plays a major role in intestinal health and nutrient absorption [2], as well as for the production of antibodies [3] and feather development [4]. In poultry, Thr deficiency has negative effects on the growth performance, carcass yield, and quality by reducing the thigh and breast yield, increasing body fat deposition, inhibiting feather development, and decreasing antibody formation, as well as having positive effects on the mortality rate [5-9]. In broiler chickens and quails, increasing the Thr levels during embryonic development improves the growth performance, mucin secretion, and the humoral immune response after hatching and feeding the supplemented diet [10-12]. In laying hens, dietary supplementation with L-Thr enhances egg production, the egg weight, feed conversion ratio (FCR), and antibody production during different phases of production and at different ambient temperature ranges [13-19]. However, to the best of our knowledge, no previous study has estimated the $\mathrm{Thr}$ requirements for laying ducks, and thus the $\mathrm{Thr}$ requirements for laying ducks are not available in the NRC [20]. Thus, the main aim of the present study was to estimate the Thr requirements of Longyan laying ducks, which are the most common laying ducks in South China, where they account for more than $60 \%$ of the laying ducks with a population size of more than 300 million birds. Longyan ducks exhibit early maturation, high egg production (280 to 300 eggs/yr), medium size, acclimatization to high ambient temperatures and disease

\section{www.ajas.info}


resistance, and their eggs are popular. We estimated the Thr requirements from 17 to $45 \mathrm{wk}$ based on the laying performance and egg quality.

\section{MATERIALS AND METHODS}

Bird management and experimental diet

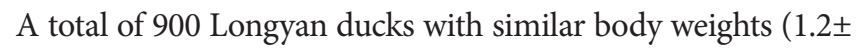
$0.01 \mathrm{~kg}$ ) and the same genetic background were allocated randomly to six dietary treatments at $17 \mathrm{wk}$ of age, where each treatment comprised six replicates with 25 ducks (each replicate was housed with an indoor area of $3 \times 1.8 \mathrm{~m}$, outdoor area of $3 \times 1.8 \mathrm{~m}$, and pool area of $3 \times 1.8 \mathrm{~m}$ ), and they were studied for $28 \mathrm{wk}$. Birds were fed the same basal diet in pellet form (Table 1), which was supplemented with $0.0 \%$ (control), $0.05 \%, 0.10 \%$, $0.15 \%, 0.20 \%$, or $0.25 \%$ of Thr in the form of L-Thr $(98.5 \% \mathrm{~L}-\mathrm{Thr}$, Tongliao Meihua Biological Sci-Tech Co. Ltd, Inner Mongolia, China). The control diet was formulated to meet the nutritional requirements of egg-laying ducks [21], with the exception of Thr. Fresh water was provided ad libitum and feed was offered twice daily with an average of $160 \mathrm{~g} / \mathrm{bird} / \mathrm{d}$, excluding any un- consumed remains. The ducks had access to the outdoor and pool areas during the daytime, but they were housed indoors at night. Natural light was available in the daytime with $4 \mathrm{~h}$ of incandescent lighting at $15 \mathrm{~lx}$ from 1,830 to 2,230. All of the experimental procedures were approved by the Animal Care and Use Committee of Guangdong Academy of Agriculture Science, China.

\section{Laying performance and egg quality parameters}

Feed intake, eggs, and broken and shell-less eggs were recorded daily on a per replicate basis. Feed intake, egg production, egg weight, egg mass, and FCR ( $g$ feed/g egg) were calculated daily on a per replicate basis, and then expressed as averages for the complete 28-wk study period.

Eight eggs were collected at random from each replicate between 37 and $45 \mathrm{wk}$ of age (three times) and the average of 48 eggs per replicate was used to evaluate the egg quality each time. An Egg Analyzer (model EA-01, 133 ORKA Food Technology, Ramat HaSharon, Israel) was used to determine the yolk color and Haugh unit score on the day of collection, and an Egg Force Reader (model EFR-01, ORKA Food Technology,

Table 1. Composition of the experimental diets and nutrient levels

\begin{tabular}{|c|c|c|c|c|c|c|}
\hline \multirow{2}{*}{ Items } & \multicolumn{6}{|c|}{ Diet } \\
\hline & Group 1 & Group 2 & Group 3 & Group 4 & Group 5 & Group 6 \\
\hline \multicolumn{7}{|l|}{ Ingredients } \\
\hline Wheat $(\%)$ & 30.00 & 30.00 & 30.00 & 30.00 & 30.00 & 30.00 \\
\hline Wheat bran (\%) & 11.50 & 11.50 & 11.50 & 11.50 & 11.50 & 11.50 \\
\hline Peanut meal (\%) & 15.60 & 15.60 & 15.60 & 15.60 & 15.60 & 15.60 \\
\hline Sodium chloride (\%) & 0.3 & 0.3 & 0.3 & 0.3 & 0.3 & 0.3 \\
\hline $\operatorname{Premix}^{1)}(\%)$ & 1.0 & 1.0 & 1.0 & 1.0 & 1.0 & 1.0 \\
\hline DL-Methionine (\%) & 0.21 & 0.21 & 0.21 & 0.21 & 0.21 & 0.21 \\
\hline L-Lysine-HCl (\%) & 0.61 & 0.61 & 0.61 & 0.61 & 0.61 & 0.61 \\
\hline L-Tryptophan (\%) & 0.04 & 0.04 & 0.04 & 0.04 & 0.04 & 0.04 \\
\hline Metabolizable energy (Kcal/kg) & 2,500 & 2,500 & 2,500 & 2,500 & 2,500 & 2,500 \\
\hline Crude protein (\%) & 16.0 & 16.0 & 16.0 & 16.0 & 16.0 & 16.0 \\
\hline Calcium (\%) & 3.6 & 3.6 & 3.6 & 3.6 & 3.6 & 3.6 \\
\hline Total P (\%) & 0.59 & 0.59 & 0.59 & 0.59 & 0.59 & 0.59 \\
\hline Available Phosphorus (\%) & 0.35 & 0.35 & 0.35 & 0.35 & 0.35 & 0.35 \\
\hline Lysine (\%) & 0.90 & 0.90 & 0.90 & 0.90 & 0.90 & 0.90 \\
\hline Methionine (\%) & 0.40 & 0.40 & 0.40 & 0.40 & 0.40 & 0.40 \\
\hline Threonine (\%) & 0.39 & 0.44 & 0.49 & 0.54 & 0.59 & 0.63 \\
\hline Tyrptophan (\%) & 0.59 & 0.59 & 0.59 & 0.59 & 0.59 & 0.59 \\
\hline Isoleucine (\%) & 0.65 & 0.65 & 0.65 & 0.65 & 0.65 & 0.65 \\
\hline Leucine (\%) & 0.94 & 0.94 & 0.94 & 0.94 & 0.94 & 0.94 \\
\hline
\end{tabular}

1) Supplied per kilogram of diet: retinyl palmitate, 12,000 IU; cholecalciferol, 2,000 IU; DL- $\alpha$-tocopheryl acetate, $38 \mathrm{mg}$; menadione sodium bisulphite, $1.0 \mathrm{mg}$; thiamin mononitrate, $3.0 \mathrm{mg}$; riboflavin, $9.6 \mathrm{mg}$; pyridoxine hydrochloride, $6.0 \mathrm{mg}$ cobalamin, $0.03 \mathrm{mg}$; chloride choline, $500 \mathrm{mg}$; nicotinic acid, $25 \mathrm{mg}$; calcium-D-pantothenate, $28.5 \mathrm{mg}$; folic acid, $0.6 \mathrm{mg}$; biotin, $0.15 \mathrm{mg}$; Fe, $50 \mathrm{mg} ; \mathrm{Cu}, 10 \mathrm{mg} ; \mathrm{Zn}, 90 \mathrm{mg} ; \mathrm{Mn}, 90 \mathrm{mg}, \mathrm{I}, 0.5 \mathrm{mg} ; \mathrm{Se}, 0.4 \mathrm{mg}$. 
Israel) was used to measure the eggshell breaking strength. The yolks were separated, weighed, and expressed as percentages relative to the egg weight. The eggshell thickness was measured using a digital micrometer based on the average of three pieces of shell with membranes from the blunt, mid-length, and pointed ends. The shells with membranes were dried to a constant weight at $105^{\circ} \mathrm{C}$ in an oven and then weighed.

\section{Statistical analysis}

The experimental data were analyzed by one-way analysis of variance using the general linear model procedure in SAS (version 9.1; SAS Institute, 22), where the pen was the experimental unit for laying performance and the individual egg served as the experimental unit for egg quality. Orthogonal polynomial contrasts were employed to test the linear and quadratic effects of Thr supplementation. A quadratic brokenline regression model was used to determine the dietary Thr requirements by performing the NLIN procedure in SAS [22], where the model used was that described by Xie et al [23].

\section{RESULTS AND DISCUSSION}

Productive performance improved in a linear or quadratic manner ( $\mathrm{p}<0.05$; Table 2$)$ as functions of increasing Thr supplementation. Our results are consistent with an earlier study of laying hens by [13], who reported that increasing the dietary Thr level significantly enhanced egg production, egg weight, and FCR. In addition, Faria et al [14] found that increasing the Thr concentration from $0.39 \%$ to $0.53 \%$ significantly increased egg production and the egg mass. Gomez and Angeles [24] observed that increasing the Thr level from $0.42 \%$ to $0.48 \%$ improved the FCR in laying hens during the second cycle of production. Cardoso et al [19] recommended increasing the Thr level from $0.523 \%$ to $0.567 \%$ to enhance egg production, the egg mass, and FCR in White Leghorn from 60 to 76 wk of age. In addition, recent studies by Azzam et al $[16,17]$ detected significant improvements in egg production when the Thr level increased from $0.47 \%$ to $0.67 \%$ from 40 to 48 wk of age, while increasing the $\mathrm{Thr}$ level from $0.57 \%$ to $0.74 \%$ from 56 to $64 \mathrm{wk}$ improved egg production and the egg mass in laying hens. In laying quails, egg production, the egg weight, and FCR were improved by increasing the Thr concentration in the diet [25]
Similar findings have been obtained in meat-type birds, including turkey toms [5], Japanese quails [6], and Pekin ducks from 1 to 21 days of age [8] and from 15 to 35 days of age [9], where the average daily weight gain and FCR increased significantly with the dietary Thr concentration. Furthermore, in chickens challenged with infectious bursal disease, the body weight gain and FCR were improved significantly by increasing the Thr concentration in the diet [7]. Moreover, fertilized eggs injected with Thr on day 14 of incubation exhibited significant improvements in their body weight gain and FCR after the chickens hatched and they were fed the same diet (without Thr supplementation) for 28 and 42 days of age [10,11]. Increasing the Thr level enhances the gut morphology and its normal development by increasing the villus height and villus height/crypt depth ratio in different parts of the intestine, thereby positively affecting nutrient absorption due to the increased villus surface area [8]. This may explain why increasing the Thr level improves egg production, the egg weight, egg mass, and FCR. By contrast, there were no effects on the FCR after increasing the Thr level from $0.81 \%$ to $1.06 \%$ in quail chicks from 1 to 35 days according to Baylan et al [26], or from $0.70 \%$ to $0.90 \%$ in broiler chickens from 22 to 42 days according to Ayasan et al [27]. These differences may be related to the Thr level in the basal diet, breed, age, and/or the experimental period.

\section{Egg quality}

As shown in Table 3, the Haugh unit score, yolk color, albumen height, egg shell quality (eggshell weight, percentage, thickness, and breaking strength) did not respond ( $p>0.05)$ to increases in the dietary Thr level. By contrast, the albumen weight and percentage increased $(\mathrm{p}<0.05)$ as the dietary $\mathrm{Thr}$ level increased, whereas the yolk weight and percentage decreased $(\mathrm{p}<0.05)$. Gomez and Angeles [24] reported that increasing the Thr level from $0.42 \%$ to $0.54 \%$ had no effects on the albumen or yolk proportions, but the egg shell percentage declined as the dietary Thr level increased when continued for 6 wks during the second cycle in laying hens. Cardoso et al [19] found that feeding white laying hens a diet containing $0.523 \%, 0.546 \%$, $0.569 \%, 0.592 \%$, or $0.615 \% \mathrm{Thr}$ for $17 \mathrm{wk}$ during the late laying period had no effects on the egg quality, including the eggshell thickness, albumen, and yolk proportion. Azzam et al [16] found that increasing the Thr level from $0.47 \%$ to $0.87 \%$ in laying hens

Table 2. Effects of dietary threonine (Thr) supplementation on the performance of laying ducks

\begin{tabular}{|c|c|c|c|c|c|c|c|c|c|c|}
\hline \multirow{2}{*}{ Item } & \multicolumn{6}{|c|}{ Dietary Thr (mg/ kg) } & \multirow{2}{*}{ SEM } & \multicolumn{3}{|c|}{$p$-value } \\
\hline & 0.39 & 0.44 & 0.49 & 0.54 & 0.59 & 0.64 & & Thr & Linear & Quadratic \\
\hline Egg production (\%) & 81.8 & 83.2 & 86.5 & 86.4 & 86.4 & 86.1 & 1.05 & 0.009 & 0.001 & 0.02 \\
\hline Egg weight (g) & 64.9 & 65.9 & 66.6 & 67.0 & 66.5 & 67.0 & 0.3 & 0.000 & 0.000 & 0.005 \\
\hline Egg mass $(g / d / d)$ & 53.0 & 54.8 & 57.6 & 57.9 & 57.5 & 57.6 & 0.7 & 0.000 & 0.000 & 0.002 \\
\hline$F\left(R^{1)}\right.$ & 3.15 & 2.95 & 2.80 & 2.79 & 2.82 & 2.81 & 0.05 & 0.000 & 0.000 & 0.002 \\
\hline
\end{tabular}

SEM, standard error of means ( $n=25$ birds/replicate; $n=6$ replicates/treatment).

1) Feed conversion ratio, $g$ of feed/g of egg mass. 
Table 3. Effects of dietary threonine (Thr) supplementation on egg quality

\begin{tabular}{|c|c|c|c|c|c|c|c|c|c|c|}
\hline \multirow{2}{*}{ Item } & \multicolumn{6}{|c|}{ Dietary Thr (mg/kg) } & \multirow{2}{*}{ SEM } & \multicolumn{3}{|c|}{$\mathrm{p}$-value } \\
\hline & 0.39 & 0.44 & 0.49 & 0.54 & 0.59 & 0.64 & & Thr & linear & Quadratic \\
\hline Haugh unit & 73.8 & 75.1 & 71.1 & 70.1 & 75.3 & 76.1 & 2.06 & 0.2 & 0.5 & 0.08 \\
\hline Yolk color & 5.83 & 6.08 & 6.08 & 6.33 & 5.75 & 5.41 & 0.32 & 0.3 & 0.4 & 0.09 \\
\hline Albumen height (mm) & 5.91 & 5.91 & 5.51 & 5.66 & 6.05 & 6.25 & 0.22 & 0.2 & 0.2 & 0.06 \\
\hline Albumen weight (g) & 38.1 & 41.8 & 40.9 & 40.0 & 41.2 & 41.4 & 0.5 & 0.001 & 0.005 & 0.07 \\
\hline Albumen (\%) & 58.8 & 63.4 & 61.3 & 59.7 & 62.0 & 61.7 & 0.7 & 0.001 & 0.1 & 0.3 \\
\hline Yolk weight (g) & 20.7 & 18.2 & 19.7 & 20.6 & 19.3 & 19.6 & 0.5 & 0.01 & 0.6 & 0.5 \\
\hline Yolk (\%) & 32.0 & 27.6 & 29.6 & 30.8 & 29.0 & 29.2 & 0.7 & 0.005 & 0.2 & 0.2 \\
\hline Eggshell weight (g) & 5.98 & 5.89 & 6.03 & 6.41 & 5.92 & 6.05 & 0.12 & 0.06 & 0.4 & 0.2 \\
\hline Eggshell (\%) & 9.21 & 8.94 & 9.05 & 9.56 & 8.90 & 9.03 & 0.18 & 0.1 & 0.7 & 0.5 \\
\hline Eggshell thickness (mm) & 0.338 & 0.332 & 0.335 & 0.338 & 0.323 & 0.327 & 0.007 & 0.6 & 0.2 & 0.7 \\
\hline Breaking strength $(\mathrm{N})$ & 4.01 & 3.75 & 3.73 & 4.54 & 3.87 & 3.94 & 0.25 & 0.2 & 0.7 & 0.7 \\
\hline
\end{tabular}

SEM, standard error of means ( $n=8$ eggs/replicate; $n=6$ replicates/treatment).

aged $40 \mathrm{wk}$ during the summer season for $8 \mathrm{wk}$ had no effect on the Haugh unit score, yolk color, eggshell thickness, or strength. In addition, feeding laying hens diets supplemented with high levels of $\operatorname{Thr}(1 \%, 2 \%$, or $3 \%)$ for two months during the post-peak period had no effects on the albumen height, Haugh unit score, yolk color, and egg shell strength, but the eggshell thickness declined in a linear manner. In brown laying hens, increasing the Thr level from $0.0 \%$ to $0.4 \%$ for $8 \mathrm{wks}$ during the late laying period had no significant effects on the albumen height, eggshell percentage, or eggshell thickness, but the Haugh unit score improved significantly [18]. Valerio et al [28] found that increasing the Thr levels in white or brown laying hens from 21 to $36 \mathrm{wk}$ of age did not change the Haugh unit score. Moreover, Sa et al [29] showed that the Haugh unit score was not affected by increasing the Thr levels in different strains of laying hens in an experiment conducted for $16 \mathrm{wk}$ (from 34-50 wk of age). Previous studies indicate that the effects of the Thr levels on egg quality may vary according to the age, strain, and experimental period. In our experiment, we found that increasing the Thr level increased the albumen weight and proportion, but decreased the yolk weight and proportion, which may explain why the egg weight increased. This finding could be due to the involvement of Thr in protein synthesis [1]. In our experiment, the control group exhibited the worst laying performance compared with the other groups because this group was fed a diet deficient in Thr. Feeding laying birds with a diet deficient in amino acids generally reduces protein production throughout the whole body, but specifically in the liver and magnum, which is responsible for albumen secretion $[30,31]$. In a previous study, increasing the concentration of amino acids increased the albumen proportion in laying hens as well as decreasing the yolk proportion [32].

In conclusion, we estimate that the dietary Thr requirement is $0.57 \%$ to achieve the maximum egg production, egg mass, and feed utilization relative to the egg mass, while a level of $0.58 \%$ is required to obtain the maximum egg weight in Longyan ducks from 17-45 wk of age.

\section{CONFLICT OF INTEREST}

We certify that there is no conflict of interest with any financial organization regarding the material discussed in the manuscript.

\section{ACKNOWLEDGMENTS}

This work was supported by the Fund for China Agricultural Research System (CARS-43-13), the Science and Technology Program of Guangdong Province (2011A020102009, 2016A 020210043) and Operating Funds for Guangdong Provincial Key Laboratory of Animal Breeding and Nutrition (2014B03 0301054).

\section{REFERENCES}

1. Kidd MT, Kerr BJ. L-threonine for poultry: A review. J Appl Poult Res 1996;5:358-67.

2. Mao X, Zeng X, Qiao S, Wu G, Li D. Specific roles of threonine in intestinal mucosal integrity and barrier function. Front Biosci 2011;3:1192-200.

3. Kidd MT. Nutritional modulation of immune function in broilers. Poult Sci 2004;83:650-7.

4. Fisher ML, Leeson S, Morrison WD, Summers JD. Feather growth and feather composition of broiler chickens. Can J Anim Sci 1981; 61:769-73.

5. Lehmann D, Pack M, Jeroch H. Effects of dietary threonine in starting, growing, and finishing turkey toms. Poult Sci 1997;76: 696-702.

6. Mandal AB, Kaur S, Johri AK, Elangovan AV, Deo C, Shrivastava HP. Response of growing Japanese quails to dietary concentration of 1-threonine. J Sci Food Agric 2006;86:793-8.

7. Taghinejad-Roudbaneh M, Babaee MJ, Afrooziyeh M, Alizadeh B. Estimation of dietary threonine requirement for growth and 
immune responses of broilers. J Appl Anim Res 2013;41:474-83.

8. Xie M, Zhang L, Wen ZG, Tang J, Huang W, Hou SS. Threonine requirement of White Pekin ducks from hatch to $21 \mathrm{~d}$ of age. $\mathrm{Br}$ Poult Sci 2014;55:553-7.

9. Zhang Q, Xu L, Doster A, et al. Dietary threonine requirement of Pekin ducks from 15 to 35 days of age based on performance, yield, serum natural antibodies, and intestinal mucin secretion. Poult Sci 2014;85:743-6.

10. Kadam MM, Bhanja SK, Mandal AB, et al. Effect of in ovo threonine supplementation on early growth, immunological responses and digestive enzyme activities in broiler chickens. Br Poult Sci 2008; 49:736-41.

11. Tahmasebi S, Toghyani M. Effect of arginine and threonine administered in ovo on digestive organ developments and subsequent growth performance of broiler chickens. J Anim Physiol Anim Nutr 2016;100:947-57.

12. Kermanshahi H, Daneshmand A, Emami NK, et al. Effect of in ovo injection of threonine on Mucin2 gene expression and digestive enzyme activity in Japanese quail (Coturnix japonica). Res Vet Sci 2015;100:257-62.

13. Martinez-Amezcua C, Laparra-Vega JL, AvilaGonzalez E, et al. Dietaryl-threonine responses in laying hens. J Appl Poult Res 1999;8:236-41.

14. Faria DE, Harms RH, Russell GB. Threonine requirement of commercial laying hens fed a corn-soybean meal diet. Poult Sci 2002; 81:809-14.

15. Azzam M, Dong XY, Xie P, Wang C, Zou XT. The effect of supplemental l-threonine on laying performance, serum free amino acids, and immune function of laying hens under hightemperature and high humidity environmental climates. J Appl Poult Res 2011;20: 361-70.

16. Azzam MMM, Zou XT, Dong XY, Xie P. Effect of supplemental L-threonine on mucin 2 gene expression and intestine mucosal immune and digestive enzymes activities of laying hens in environments with high temperature and humidity. Poult Sci 2011;90: 2251-6.

17. Azzam MMM, Yuan C, Liu GH, Zou XT. Effect of excess dietary threonine on laying performance, egg quality, serum free amino acids, and digestive enzymes activities of laying hens during the postpeak period. J Appl Poult Res 2014;23:605-13.

18. Abdel-Wareth AAA, Esmail ZSH. Some productive, egg quality and serum metabolic profile responses due to l-threonine supplementation to laying hen diets. Asian J Poult Sci 2014;8:75-81.
19. Cardoso AS, Costa FGP, de Lima MR, et al. Nutritional requirement of digestible threonine for white egg layers of 60 to 76 weeks of age. J Appl Poult Res 2014;23:724-8.

20. National Research Council. Nutrient requirements of poultry. 9th ed. Washington, DC: National Academy Press; 1994.

21. Ruan D, Lin Y, Chen W, et al. Effects of rice bran on performance, egg quality, oxidative status, yolk fatty acid composition, and fatty acid metabolism-related gene expression in laying ducks. Poult Sci 2015;94:2944-51.

22. SAS Institute. SAS User's Guide: Statistics. Version 9.1. SAS Institute, Inc., Cary, NC; 2004.

23. Xie M, Guo Y, Zhang T, Hou S, Huang W. Lysine requirement of male White Pekin ducklings from seven to twentyone days of age. n-australas J Anim Sci 2009;22:1386-90.

24. Gomez S, Angeles M. Effect of threonine and methionine levels in the diet of laying hens in the second cycle of production. J Appl Poult Res 2009;18:452-7.

25. Canogullari S, Baylan M, Ayasan T. Threonine requirement of laying Japanese quails. J Anim Vet Adv 2009;8:1539-41.

26. Baylan M, Canogullari S, Ayasan T, Sahin A. Dietary threonine supplementation for improving growth performance and edible carcass parts in japanese quails, Coturnix coturnix japonica. Int J Poult Sci 2006;5:635-8.

27. Ayasan T, Okan F, Hizli H. Threonine requirement of broiler from 22-42 days. Int J Poult Sci 2009; 8:862-5.

28. Valério SR, Soares PR, Rostagno HS, et al. Determination of threonine nutritional requirement for white-egg and brown-egg laying hens.. R Bras Zootec 2000;29:518-24.

29. Sa LM, Gomes PC, Cecon PR, Rostagno HS, D’Agostini P. Nutritional requirement of digestible threonine for light-weight and semi-heavy laying hens in the period from 34 to 50 weeks old. $\mathrm{R}$ Bras Zootec 2007;36:1846-53.

30. Hiramoto K, Muramatsu T, Okumura J. Effect of methionine and lysine deficiencies on protein synthesis in the liver and oviduct and in the whole body of laying hens. Poult Sci 1990;69:84-9.

31. Yuan C, Bu XC, Yan HX, Lu JJ, Zou XT. Dietary L-arginine levels affect the liver protein turnover and alter the expression of genes related to protein synthesis and proteolysis of laying hens. Poult Sci 2016;95:261-7.

32. Novak C, Yakout H, Scheideler S. The combined effects of dietary lysine and total sulfur amino acid level on egg production parameters and egg components in Dekalb Delta laying hens. Poult Sci 2004;83:977-84. 